\title{
Effect of Phototherapy on Serum Zinc Level in Neonatal Jaundice Abdulmagid Mohammed Baiomi ${ }^{1}$, Khaled Hassaan Hassan ${ }^{1}$, Mohammed Ahmed Besher ${ }^{2}$, Mahmoud Hussein Mahmoud*1 \\ Departments of ${ }^{1}$ Pediatrics \& Neonatology and ${ }^{2}$ Clinical Pathology, Faculty of Medicine, Al- Azhar University, Assiut \\ *Corresponding author: Mahmoud Hussein Mahmoud, Mobile: (+20) 01065272779, E-Mail: Drmahmoudhussein777@gmail.com
}

\begin{abstract}
Background: Zinc salts can reduce phototherapy duration by precipitating unconjugated bilirubin in the intestine however, zinc toxicity is an issue that must be considered. Theoretically, bilirubin reduction by phototherapy may increase serum zinc levels, making additional zinc supplementation, which cause zinc toxicity.

Objectives: To evaluate serum zinc level alterations before and after phototherapy in hyperbilirubinemic newborns.

Materials and Methods: A prospective cross sectional case-control study was performed at Neonatal Intensive Care Unit (NICU), Al-Azhar University Hospital, Assiut. 150 newborns aged between 2-7 days divided into 50 healthy neonates without hyperbilirubinemia (control group) and 100 neonates with physiological jaundice who required phototherapy (case group). Participants were treated according to American Academy of Pediatrics (AAP) criteria. Serum zinc level was measured before and after phototherapy.

Results: The mean age of onset was approximately 2 days, while the majority of patients were females and delivered with cesarean section. The age at admission was $3.09 \pm 0.57$ days. In regard to our primary outcomes, serum bilirubin level was decreased significantly after phototherapy to reach $8.47 \pm 1.36 \mathrm{mg} / \mathrm{dl}$ ( $p<0.001)$. Serum zinc level was increased significantly after phototherapy to reach $75.45 \pm 14.94 \mathrm{mcg} / \mathrm{mL}(\mathrm{p}<0.001)$. The comparison between control and study groups regarding serum zinc level showed that there was highly statistically significant difference being higher in case group compared to control group $(\mathrm{p}<0.001)$. Phototherapy was associated with a significant increase in serum zinc level in neonates.
\end{abstract}

Conclusions: Phototherapy increases serum zinc level by reducing bilirubin level so additional supplementation of this element can lead potentially zinc toxicity.

Keywords: Hyperbilirubinemia, Zinc, Phototherapy, Neonatal Jaundice.

\section{INTRODUCTION}

Bilirubin is produced by the catabolism of heme in the reticuloendothelial system. This bilirubin is in an unconjugated form and is released into the circulation and transported to hepatocytes where it combines enzymatically with glucuronic acid, producing bilirubin mono- and diglucuronides. The conjugation reaction is catalyzed by uridine diphosphate glucuronosyl transferase ${ }^{(\mathbf{1})}$.

Jaundice, or yellowish discoloration of the skin, can occur due to an increased amount of bilirubin pigment in the blood (2). Neonates with severe hyperbilirubinemia are endangered because of possible accumulation of bilirubin in tissues, particularly in the brain causing acute bilirubin encephalopathy and its chronic sequelae such as cerebral palsy, sensorineural hearing loss, intellectual difficulties or gross developmental delays ${ }^{(3)}$.

Phototherapy is the single most common intervention used for the treatment of neonatal jaundice. The greater the surface area exposed, the greater the effectiveness of phototherapy ${ }^{(4)}$. Several lines of evidence suggest the importance of intestinal metabolism of unconjugated bilirubin (UCB) in the pathogenesis of neonatal jaundice ${ }^{(5)}$. Moreover, it has been recently postulated that increased enterohepatic circulation (EHC) of bilirubin may occur with ileal inflammation, resection or bypass resulting in biliary hypersecretion of bilirubin with enhanced black pigment gallstone formation ${ }^{(6)}$.

The existence of EHC bilirubin was first described in early 1960s when radiolabeled bilirubin became available. Based on the data, it was suggested that bilirubin must be deconjugated before reabsorption from the intestine. As no active transport for UCB has been proved in the intestine, bilirubin may cycle enterohepatically only by passive diffusion under specific conditions that occur, for instance, during the neonatal period or in patients with pathology of the distal ileum. Interestingly, only one third of bilirubin reabsorbed from the intestine is cleared by the liver during the first pass; the remainder may enter the systemic circulation ${ }^{(\boldsymbol{(})}$.

Enterohepatic Circulation (EHC) may be exaggerated in the neonatal period, in part because the newborn intestinal tract is not yet colonised with bacteria that convert unconjugated bilirubin (UCB) to urobilinogen and because intestinal beta glucuronidase activity is high ${ }^{(7)}$. 
Zinc is one of the essential elements in neonatal growth, protein synthesis and regulation of inhibitory and stimulatory synapses of the brain. Zinc lowers bilirubin levels by inhibition of the normal enterohepatic circulation of unconjugated bilirubin (UCB) ${ }^{(8)}$.

The chemical structure of bilirubin has the potential to chelate metal ions, such as zinc. As a result, bilirubin reduction by phototherapy may cause an increase in serum zinc levels. In this situation, additional zinc supplementation may bring about zinc toxicity ${ }^{(9)}$.

This work aimed to evaluate serum zinc level alterations before and after phototherapy in hyperbilirubinemic newborns.

\section{PATIENTS AND METHODS}

A prospective cross sectional case-control study included 150 newborns that were randomly selected and fulfilled the inclusion and exclusion criteria and treated at NICU of Al-Azhar University Hospital in Assiut through 1 year.

The study included 150 full term neonate aged (GA $>37$ weeks) between 2-7 days divided into 2 groups:

- Control group: 50 healthy neonates not suffering from hyperbilirubinemia or any other problems.

- $\quad$ Case group: 100 full term healthy neonates with indirect hyperbilirubinemia (non-hemolytic jaundice) that required phototherapy according to American Academy of Pediatrics (AAP) criteria $^{(10)}$.

- Inclusion Criteria: Full-term newborns (GA > 37 weeks), birth weight $>2500 \mathrm{gm}$ and with clinically evident jaundice with an onset between 2-7 days.

- Exclusion Criteria: Newborn undergoing exchange transfusion, apparent congenital anomalies and sepsis.

\section{Ethical considerations:}

The present study was conducted in concordance with international ethical standards and applicable local regulatory rules. We gained approval of Academic and Ethical Committee, Al-Azhar University Hospital, Assiut. Every patient's parent signed an informed written consent for acceptance of the treatment.

All patients and controls included in the study were subjected to the following:

1- Detailed maternal, obstetric and neonatal history: Maternal data included gravidity, parity, maternal illness and medications, Obstetric history. Neonatal data included gestational age, birth weight, and onset of neonatal jaundice and duration of hospital stay and outcome (survival or mortality) and family history.
2- Clinical data: Weight, length. Gestational age. Vital signs. Neonatal reflexes. Examination to assess zinc toxicity.

\section{Investigations:}

1. Determination of serum bilirubin: Serial serum bilirubin measurements were repeated on daily bases. Total serum bilirubin direct and indirect bilirubin was measured.

2. Blood group and RH determination: The $A B O$ and Rhesus blood grouping was done to the mother and the baby to rule out $\mathrm{ABO}$ an $\mathrm{Rh}$ incompatibility as a cause of jaundice.

3. To exclude hemolysis: Hemoglobin, hematocrit levels and reticulocytic count were also done.

4. To exclude sepsis: Determination of CRP, CBC

5. Specific investigations: Serum zinc level once for control group and before and after phototherapy in case group.

\section{Serum $\mathrm{Zn}$ assay:}

The determination of serum zinc levels were carried out by atomic absorption spectrometry method using A-Analyst 800(Perkin Elmer USA).

- Sampling: Venous blood samples ( $2 \mathrm{ml}$ from each newborn) were obtained from all patients for zinc level analysis using plain vacutainer. Samples were withdrawn before phototherapy and after phototherapy. After extraction, the whole blood was centrifuged and serum $(500-1000 \mu \mathrm{L})$ was separated and transferred into milliliter sterile conic tubes and stored at $-20^{\circ} \mathrm{C}$ until analysis. Hemolyzed samples were rejected.

- Procedure for analysis of serum zinc: Serum zinc level according to the instrument: 50 - 150 $\mathrm{mcg} / \mathrm{ml}$. Toxic level $>200 \mathrm{mcg} / \mathrm{ml}$

- Sample preparation: Allow serum samples to come to room temperature and dilute the sample 1:5 with deionized water ${ }^{(\mathbf{1 1})}$.

\section{Analysis}

The analysis is performed against standards prepared in glycerol to approximate the viscosity characteristics of the diluted samples. We measured the concentration of zinc using Zinc standards, which are prepared by diluting the stock standard solution, for zinc (Dissolving $0.500 \mathrm{~g}$ of zinc metal in a minimum volume of $(1+1) \mathrm{HC} 1$ and dilute to 1 liter with $1 \%(\mathrm{v} / \mathrm{v}) \mathrm{HCl}$ and $5 \%(\mathrm{v} / \mathrm{v})$ glycerol. A $5 \%(\mathrm{v} / \mathrm{v})$ glycerol solution should be used as a blank solution.

Phototherapy Procedure: With three standard phototherapy units containing blue lamps (2W/250, B6 model; Philips, Egypt, $58.8 \mathrm{~cm}$ in length, $38 \mathrm{~mm}$ in diameter and $57 \mathrm{~V} / 0.38 \mathrm{Amp}$ ), conventional phototherapy was applied through two directions. The extensive phototherapy was bilisphere 360 phototherapy lamps, which is bilicot LED phototherapy. The spectral irradiance was approximately $12 \mu \mathrm{W} / \mathrm{cm} 2 / \mathrm{nm}$. 
Phototherapy was applied continually after hospital admission at a $40-\mathrm{cm}$ distance to the babies, which were completely nude except for a diaper, lying inside the incubator, whose eyes were covered with a special eye protection band. During the procedure, the patients were taken away from phototherapy only for feeding for 15-20 minutes every 3 hours as well as for brief examination and blood-collection periods.

\section{Statistical analysis}

Recorded data were analyzed using the statistical package for social sciences, version 20.0 (SPSS Inc.,
Chicago, Illinois, USA). Quantitative data were expressed as mean \pm standard deviation (SD). Qualitative data were expressed as frequency and percentage. Independent-samples t-test of significance was used when comparing between two means.

Chi-square $\left(\mathrm{x}^{2}\right)$ test of significance was used in order to compare proportions between two qualitative parameters. The confidence interval was set to $95 \%$ and the margin of error accepted was set to $5 \%$. The p-value was considered significant as the following: $\mathrm{P} \leq 0.05$ was considered significant. $\mathrm{P}<$ 0.001 was considered as highly significant. $\mathrm{P}>0.05$ was considered insignificant.

\section{RESULTS}

Serum zinc was measured with serum bilirubin on admission and at discharge for the case group and once for the control group.

Table (1): Description of the demographic data of the hyperbilirubinemic newborns

\begin{tabular}{|l|l|c|}
\hline \multicolumn{2}{|c|}{} & Total no. $=\mathbf{1 0 0}$ \\
\hline \multirow{2}{*}{ Sex } & Male & $47(47.0 \%)$ \\
\cline { 2 - 2 } & Female & $53(53.0 \%)$ \\
\hline \multirow{2}{*}{ Mode of delivery } & NVD & $16(16.0 \%)$ \\
\cline { 2 - 2 } & CS & $84(84.0 \%)$ \\
\hline GA & Mean \pm SD & $38.00 \pm 0.00$ \\
\hline Wt. (kgs) & Mean \pm SD & $3.03 \pm 0.16$ \\
\hline Age of onset (Days) & Mean \pm SD & $2.13 \pm 0.34$ \\
\hline Age of admission (Days) & Mean \pm SD & $3.09 \pm 0.57$ \\
\hline Age of discharge (Days) & Mean \pm SD & $6.56 \pm 0.86$ \\
\hline
\end{tabular}

This table concerned with the demographic data of our case study group showed that the mean age of onset was $2.13 \pm 0.34$ days. The majority of patients were females (53 females VS 47 males). Most were delivered by cesarean section (16 by NVD VS 84 by CS). The age at admission was $3.09 \pm 0.57$ days and the age of discharge was $6.56 \pm 0.86$ days.

Table (2): The phototherapy characteristics of the hyperbilirubinemic newborns

\begin{tabular}{|l|c|c|}
\hline \multicolumn{2}{|c|}{} & Total no. $=\mathbf{1 0 0}$ \\
\hline \multirow{2}{*}{ Type of phototherapy } & Conventional & $41(41.0 \%)$ \\
\hline & Extensive & $59(59.0 \%)$ \\
\hline Duration of photo (hours) & Mean \pm SD & $57.72 \pm 12.02$ \\
\hline Serum Bilirubin level before phototherapy $(\mathrm{mg} / \mathrm{dl})$ & Mean \pm SD & $18.93 \pm 1.74$ \\
\hline Serum Bilirubin level after phototherapy $(\mathrm{mg} / \mathrm{dl})$ & Mean \pm SD & $8.47 \pm 1.36$ \\
\hline Serum Zinc level before phototherapy $(\mathrm{mcg} / \mathrm{dl})$ & Mean \pm SD & $61.36 \pm 18.25$ \\
\hline Serum Zinc level after phototherapy $(\mathrm{mcg} / \mathrm{dl})$ & Mean \pm SD & $75.45 \pm 14.94$ \\
\hline
\end{tabular}

This table showed that a higher proportion of patients with severe hyperbilirubinemia underwent intensive phototherapy (59 vs 41) with a mean phototherapy duration of $57.72 \pm 12.02 \mathrm{hrs}$. The bilirubin level decreased significantly after phototherapy (mean serum bilirubin level before phototherapy was $18.93 \pm 1.74 \mathrm{mg} / \mathrm{dl}$ VS 8.47 $\pm 1.36 \mathrm{mg} / \mathrm{dl}$ after phototherapy). Also, Zinc level increased significantly after phototherapy (mean serum zinc level before phototherapy was $61.36 \mathrm{mcg} / \mathrm{dl} \pm 18.25 \mathrm{VS} 75.45 \pm 14.94 \mathrm{mcg} / \mathrm{dl}$ after phototherapy). 
Table (3): Comparison of the laboratory data between the control and patients group (N150)

\begin{tabular}{|l|c|c|c|c|}
\hline \multicolumn{2}{|c|}{} & Control group & Patients group & \multirow{2}{*}{ P-value } \\
\cline { 3 - 4 } \multicolumn{2}{|c|}{} & No. $=\mathbf{5 0}$ & No. $=\mathbf{1 0 0}$ & \\
\hline Reticulocytes $(\%)$ & Mean \pm SD & $3.57 \pm 0.54$ & $3.58 \pm 0.54$ & 0.958 \\
\hline Hb $(\mathrm{g} / \mathrm{dl})$ & Mean \pm SD & $15.16 \pm 1.62$ & $15.16 \pm 1.62$ & 0.994 \\
\hline HCT $(\%)$ & Mean \pm SD & $47.74 \pm 5.43$ & $47.70 \pm 5.41$ & 0.965 \\
\hline TLC (thousand/mm $\left.{ }^{3}\right)$ & Mean \pm SD & $14.58 \pm 3.45$ & $14.69 \pm 3.38$ & 0.854 \\
\hline \multirow{2}{*}{ Shift to left } & No & $50(100.0 \%)$ & $100(100.0 \%)$ & - \\
\hline CRP $(\mathrm{mg} / \mathrm{L})$ & Yes & $0(0.0 \%)$ & $0(0.0 \%)$ & - \\
\hline \multirow{2}{*}{ Hemolysis } & Mean \pm SD & $4.80 \pm 1.97$ & $5.04 \pm 1.04$ & 0.647 \\
\hline \multirow{2}{*}{ Sepsis } & No & $50(100.0 \%)$ & $100(100.0 \%)$ & - \\
& Yes & $0(0.0 \%)$ & $0(0.0 \%)$ & - \\
\hline
\end{tabular}

P-value > 0.05: Non-significant. P-value < 0.05: Significant. $\quad$ P-value $<0.01$ : Highly significant

$\bullet:$ Independent t-test

This table concerned with the laboratory data of control and study groups showed that there was no significant difference between the two groups regarding reticulocytic count, mean hemoglobin level, mean hematocrit level, mean total leucocytic count and CRP of the baby $(\mathrm{P}=0.958,0.994,0.965,0.854,0.647$ respectively). Regarding both groups the sepsis profile showed that there was no shift to the left and no hemolysis occurred in both groups.

Table (4): Comparison between control and patients groups regarding serum zinc level (N150) before phototherapy

\begin{tabular}{|c|c|c|c|c|}
\hline \multicolumn{2}{|c|}{} & Control group & Patients group & \multirow{2}{*}{ P-value } \\
\cline { 3 - 4 } & No. $=\mathbf{5 0}$ & No. $=\mathbf{1 0 0}$ & \\
\hline Zinc before & Mean \pm SD & $84.8 \pm 11.41$ & $61.36 \pm 18.25$ & 0.000 \\
\hline
\end{tabular}

P-value > 0.05: Non-significant. P-value < 0.05: Significant. P-value < 0.01: Highly significant

This table showed that highly statistically significant difference between serum zinc level at control and study group (p-value $<0.001$ ) being higher in control group.

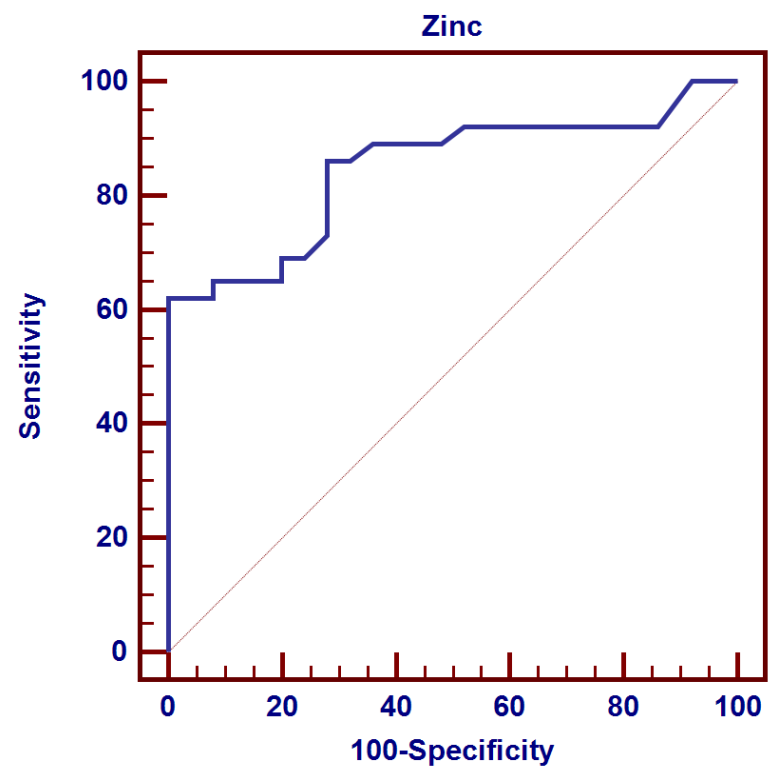

\begin{tabular}{|c|c|c|c|c|c|}
\hline Cut off point & AUC & Sensitivity & Specificity & +PV & PV \\
\hline$\leq 59$ & 0.846 & 62.00 & 100.00 & 100.0 & 56.8 \\
\hline
\end{tabular}

Figure (1): Cut-off point of serum zinc level in control and patients group.

This figure showed that the cutoff point in our study group was $\leq 59$ with sensitivity $62 \%$ and specificity $100 \%$. 
Table (5): Serum bilirubin and zinc levels in patients group (N100) before and after phototherapy

\begin{tabular}{|c|c|c|c|c|c|}
\hline \multicolumn{2}{|l|}{} & $\begin{array}{c}\text { Before } \\
\text { phototherapy } \\
(\mathbf{1 0 0} \text { cases })\end{array}$ & $\begin{array}{c}\text { After } \\
\text { phototherapy } \\
(\mathbf{1 0 0} \text { cases })\end{array}$ & Mean \pm SD & P-value \\
\hline Bilirubin (mg/dl) & Mean \pm SD & $18.93 \pm 1.74$ & $8.47 \pm 1.36$ & $-10.46 \pm 1.57$ & $<0.001$ \\
\hline Zinc (mcg/dl) & Mean \pm SD & $61.36 \pm 18.25$ & $75.45 \pm 14.94$ & $14.09 \pm 11.43$ & $<0.001$ \\
\hline
\end{tabular}

P-value > 0.05: Non-significant. $\quad$ P-value < 0.05: Significant.

$\because$ Paired t-test

P-value < 0.01: Highly significant

This table showed that there was highly statistically significant difference between before and after phototherapy regarding mean serum bilirubin and zinc levels $(\mathrm{p}<0.001)$.

Table (6): The correlation between serum zinc level before and after phototherapy and some clinical and laboratory characteristics in patients group $(\mathrm{N}=100)$

\begin{tabular}{|l|c|c|c|c|}
\hline \multirow{2}{*}{} & \multicolumn{2}{|c|}{ Zinc before } & \multicolumn{2}{c|}{ Zinc After } \\
\cline { 2 - 5 } & $\mathbf{R}$ & P-value & r & P-value \\
\hline Wt (kgs) & 0.013 & 0.895 & -0.202 & 0.144 \\
\hline Age of onset (Days) & 0.285 & 0.114 & 0.114 & 0.259 \\
\hline Age of admission (Days) & -0.103 & 0.307 & -0.024 & 0.813 \\
\hline Age of discharge (Days) & -0.102 & 0.311 & -0.193 & 0.054 \\
\hline Retics (\%) & 0.252 & 0.211 & 0.279 & 0.205 \\
\hline Hb (g/dl) & -0.130 & 0.199 & 0.109 & 0.281 \\
\hline HCT $(\%)$ & -0.091 & 0.366 & 0.151 & 0.134 \\
\hline TLC $(* 1000 /$ cm) & 0.248 & 0.113 & 0.506 & 0.123 \\
\hline CRP (mg/L) & 0.044 & 0.667 & -0.114 & 0.258 \\
\hline $\begin{array}{l}\text { Serum bilirubin level before and after } \\
\text { photo (mg/dl) }\end{array}$ & $\mathbf{- 0 . 2 5 2 *}$ & $\mathbf{0 . 0 1 2}$ & $\mathbf{- 0 . 2 1 8 *}$ & $\mathbf{0 . 0 2 9}$ \\
\hline Duration of phototherapy (hours) & - & - & $\mathbf{0 . 4 2 9 * *}$ & $\mathbf{0 . 0 0 0}$ \\
\hline
\end{tabular}

P-value > 0.05: Non-significant. P-value < 0.05: Significant. Spearman correlation coefficient

Concerning serum bilirubin level before phototherapy, there was a negative significant correlation with serum zinc level before phototherapy $(\mathrm{R}=0.252$, $\mathrm{p}$-value $=0.012)$. Our correlation analysis showed that the correlation between serum zinc level after phototherapy and the duration of phototherapy was highly significant $(\mathrm{R}$ $=0.429$, p-value $=0.000$ ). Regarding serum bilirubin level after phototherapy, there was a negative significant correlation with serum zinc level after phototherapy $(\mathrm{R}=0.218$, $\mathrm{p}$-value $=0.029)$.

\section{DISCUSSION}

The mean age of onset in case group was approximately two days. Pathological, hemolyticjaundice usually appears within $24 \mathrm{hrs}$ due to increase in serum bilirubin beyond $5 \mathrm{mg} / \mathrm{dl} / \mathrm{day}{ }^{(12)}$. The average age of admission of case group was 3.09 \pm 0.57 days. Previous reports have shown that the average age of admission was approximately three and half days in patients with severe hyperbilirubinemia ${ }^{(13)}$. Mosayebi et al. ${ }^{(14)}$ in their study of serum zinc levels in hyperbilirubinemic neonates before and after phototherapy showed that the average age of admission was $5.7 \pm 2.9$ days in patients with severe hyperbilirubinemia.

In addition, the majority of patients were males $(53 \%)$ and $84 \%$ of the study group were delivered via cesarean section. Saravanan and Raghuram ${ }^{(15)}$ in a study about zinc toxicity as a complication of phototherapy found that $50 \%$ of the study group were males and $66 \%$ of the study group were born by cesarean section. Najib et al. (16) performed a cross-sectional study to assess the characteristics of all infants less than 28 days referred due to severe indirect hyperbilirubinemia. In their study, 58\% of the included patients were males, however, only $26.5 \%$ of them delivered via cesarean section method. The difference in the rates of cesarean section method between our results and the above-mentioned study can be attributed to the steady rise in cesarean section method in Egypt that has reached an alarming level in recent years. This increase appears to be associated with a shift towards delivery in private health care facilities rather than an increased level of indications ${ }^{(\mathbf{1 7})}$.

Concerning the type of phototherapy, there were a statistically significant higher proportion of 
patients who underwent intensive phototherapy (59\% intensive versus $41 \%$ conventional phototherapy), which is coincident with Mosayebi et al. ${ }^{(14)}$ who showed that $51 \%$ underwent intensive phototherapy. The current evidence indicates that aggressive implementation of phototherapy results in a clinically significant rate of bilirubin decrease, and that neonate with severe hyperbilirubinemia needs more excessive photo to reduce the need for exchange transfusion and possibly reduce the severity of bilirubin neurotoxicity ${ }^{(\mathbf{1 8})}$.

In addition, our analysis showed that the duration of phototherapy was $2.4 \pm 0.5$ days, which is similar to Mosayebi et al. ${ }^{(14)}$ and Saravanan and Raghuram ${ }^{(15)}$ where the duration was $2.4 \pm 0.6$ days in both studies.

Our analysis showed that the duration of phototherapy was significantly shorter among patients who received intensive phototherapy with a mean duration of 52 hours compared to 66.2 hours among patients who received conventional phototherapy. In addition, Raid et al. ${ }^{(19)}$ showed that the duration of conventional phototherapy (group 1) was $8.6 \pm 2.2$ hours and $4.1 \pm 1.25$ hours for patients who received intensive phototherapy (group 2). The decline rate in group 1 was $0.2 \mathrm{mg}$ per hour while in group 2 was $1.3 \mathrm{mg}$ per hour. Phototherapy using intensive modalities was reported to be more effective at reducing the number of hours spent under intensive phototherapy compared with conventional phototherapy (using halogen-quartz bulbs) in term and preterm infants ${ }^{(20)}$. This may explain the shorter duration of phototherapy among patients with higher serum bilirubin levels ${ }^{(21)}$.

In our study analysis, we found that there was highly statistically significant difference in serum zinc level between control (healthy) and case (jaundiced) groups before phototherapy (the mean value of serum zinc level was $84.8 \pm 11.41$ in control group versus $61.36 \pm 18.25$ in patients' group before phototherapy $(\mathrm{p}<0.001)$. This is in agreement with Boskabadi et al. ${ }^{(22)}$ who found that serum zinc level of the neonates with jaundice was lower than that of the ones without jaundice (control group) ( $\mathrm{P}<$ 0.001)). In addition, Ali et $\boldsymbol{a l} .{ }^{(23)}$ reported that the level of serum zinc in neonates with non-hemolytic hyperbilirubinemia was $103.3 \pm 36.56 \mathrm{ug} / \mathrm{dl}$, which was significantly lower than that in healthy neonates without jaundice $(128.62 \pm 40.83 \mathrm{ug} / \mathrm{dl})$.

Regarding case group, we found that there was a significant negative correlation between serum bilirubin and serum zinc level before phototherapy ( $\mathrm{r}$ $=-0.252, \mathrm{P}=0.012)$. This result is in concordance with Ali et al. ${ }^{(23)}$ who showed that there was a negative correlation between serum zinc and TSB. As well, Ali et al. ${ }^{(23)}$ reported that zinc deficiency in jaundiced neonates $(25.3 \%)$ was statistically significant more than in healthy neonates $(6.7 \%)$.
Also In our study, we found that there was a significant negative correlation between serum bilirubin and serum zinc level after phototherapy $(\mathrm{r}=$ $-0.218, P=0.029)$. Saravanan and Raghuram ${ }^{(15)}$ reported that there was significant negative correlation between serum bilirubin and serum zinc levels before phototherapy $(\mathrm{r}=-0.31, \mathrm{P}=0.01)$ and after phototherapy $(\mathrm{r}=-0.4, \mathrm{P}=0.01)$.

About our primary outcomes, the present study showed that serum zinc level increased significantly after phototherapy in our study group (75.45 \pm 14.94; p-value $<0.001)$. This is in concordance with Saravanan and Raghuram (15) who performed a prospective cohort study to estimate serum zinc level alterations before and after phototherapy, in jaundiced newborns. Their results showed that phototherapy was associated with a significant increase in serum zinc level in neonates with (TSB $>18 \mathrm{mg} / \mathrm{dL}$ ) but not in those with (TSB $<18 \mathrm{mg} / \mathrm{dL}$ ). In contrary to our findings, ElMazary et $\boldsymbol{a l} .{ }^{(21)}$ assessed the changes in serum levels of a number of trace elements (copper, zinc, and magnesium) following phototherapy in full term neonates with indirect hyperbilirubinemia. The results showed that intensive phototherapy increased mean serum copper and magnesium levels in neonates with hyperbilirubinemia significantly, but it had no effect on serum zinc level and did not change it significantly. Saravanan and Raghuram (15) reported that phototherapy caused a significant increase in the level of zinc with potentially toxic levels (zinc > $200 \mathrm{mcg} / \mathrm{dl}$ ) in neonates with TSB more than $18 \mathrm{mg} / \mathrm{dl}$. Similarly, Mosayebi et al. ${ }^{(14)}$ showed that there was a significant increase in the percentage of neonates with zinc levels > 200 $\mathrm{mcg} / \mathrm{dL}$ after phototherapy in neonates with TSB more than $18 \mathrm{mg} / \mathrm{dl}$.

The sample size of the present study was relatively small, which may affect the generalizability of our findings.

\section{CONCLUSION}

Phototherapy causes significant increase in serum zinc level, regardless of the severity of hyperbilirubinemia. However, it may induce zinc toxicity. Future research should be directed towards evaluating the safety of zinc salts for lowering bilirubin levels in neonates with hyperbilirubinemia.

\section{RECOMMENDATIONS}

1. Further researches on the efficacy of zinc salts in inhibition of enterohepatic circulation for treatment of hyperbilirubinemia, but with using insoluble zinc salts to avoid zinc toxicity.

2. More studies in evaluation of the role of phototherapy in rising serum zinc in hyperbilirubinemia. 


\section{REFERENCES}

1. Reshetnyak V (2013): Physiological and molecular biochemical mechanisms of bile formation. World journal of gastroenterology: WJG., 19 (42): 7341-44.

2. Constantin T (2011): Jaundice obstructive syndrome. Current Health Sciences Journal, 37 (2): 10-13.

3. Das S, van Landeghem FK (2019): Clinicopathological Spectrum of Bilirubin Encephalopathy/Kernicterus. Diagnostics, 9 (1): 24.

4. Bhutani V, Committee on Fetus and Newborn, American Academy of Pediatrics (2011): Phototherapy to prevent severe neonatal hyperbilirubinemia in the newborn infant 35 or more weeks of gestation. Pediatrics, 128 (4): 1046-52.

5. Jangi S, Otterbein L, Robson S (2013): The molecular basis for the immunomodulatory activities of unconjugated bilirubin. The International Journal of Biochemistry \& Cell Biology, 45 (12): 2843-2851.

6. Vitek L, Muchova L, Zelenka J et al. (2005): The effect of zinc salts on serum bilirubin levels in hyperbilirubinemic rats. Journal of Pediatric Gastroenterology and Nutrition, 40 (2): 135-140.

7. Cuperus F, Hafkamp A, Havinga $R$ et al. (2009): Effective treatment of unconjugated hyperbilirubinemia with oral bile salts in Gunn rats. Gastroenterology, 136 (2): 673-682.

8. Hashemian S, Mohammadzadeh A, Farhat A et al. (2017): The Therapeutic Effect of Zinc Sulfate on Neonatal Hyperbilirubinemia. Iranian Journal of Neonatology, 8 (2): 13-17.

9. Blindauer $\mathbf{C}$ (2013): Lessons on the critical interplay between zinc binding and protein structure and dynamics. J Inorg Biochem., 121: 145-155.

10. American Academy of Pediatrics (2004): Management of hyperbilirubinemia in the newborn infant 35 or more weeks of gestation. Clinical Practice Guideline. Pediatrics, 114 (4): 297-316.

11. Makino T, Takahara K (1981): Direct determination of plasma copper and zinc in infants by atomic absorption with discrete nebulization. Clinical Chemistry, 27 (8): 1445-7.

12. Ullah S, Rahman K, Hedayati M (2016): Hyperbilirubinemia in neonates: Types, causes, clinical examinations, preventive measures and treatments: A narrative review article. Iranian Journal of Public Health, 45 (5): 558-568.
13. Yu C, Li H, Zhang Q (2017): Report about term infants with severe hyperbilirubinemia undergoing exchange transfusion in Southwestern China during an 11-year period, from 2001 to 2011. PLoS One, 12 (6): $179-550$.

14. Mosayebi Z, Rahmani M, Ardakani $S$ et al. (2016): Evaluation of serum zinc levels in hyperbilirubinemic neonates before and after phototherapy. Iranian Journal of Pediatrics, 26(3).

15. Saravanan S, Raghuram A (2017): Incidence of Zinc Toxicity as a Complication of Phototherapy, JMSCR., 5 (4): 20232-20236.

16. Najib K, Saki F, Hemmati F et al. (2013): Incidence, risk factors and causes of severe neonatal hyperbilirubinemia in South of Iran (Fars Province). Iranian Red Crescent Medical Journal, 15 (3): 1-4.

17. Al Rifai $\mathbf{R}$ (2017): Trend of caesarean deliveries in Egypt and its associated factors: Evidence from national surveys, 2005-2014. BMC Pregnancy and Childbirth, 17 (1): 24-30.

18. Hansen $T$, Nietsch $L$, Norman $E$ (2009): Reversibility of acute intermediate phase bilirubin encephalopathy. Acta Paediatrica, International Journal of Paediatrics, 98 (10): 1689-1694.

19. Raid U (2012): Effectiveness of 360。 Intensive Phototherapy versus Conventional Phototherapyfor Neonatal Hyperbilirubinemia. Kufa Medical Journal, 15 (1): 204-210.

20. Woodgate $\mathbf{P}$, Jardine $\mathbf{L}$ (2015): Neonatal jaundice: phototherapy. BMJ Clinical Evidence, 2015:0319.

21. El-Mazary A, Abdel Aziz R, Sayed $M$ et al. (2017): Effect of Intensive Phototherapy and Exchange Transfusion on Copper, Zinc and Magnesium Serum Levels in Neonates with Indirect Hyperbilirubinemia. International Journal of Pediatrics, 5 (2): 4371-4383.

22. Boskabadi H, Maamouri G, Zadeh H et al. (2015): Comparison of Serum Zinc Level Between Neonates with Jaundice and Healthy Neonates. Shiraz E-Med J., 16 (10): e27392.

23. Ali $\mathrm{S}$, Abdel-aal M, Elsamanoudy $M$ et al. (2020): Serum Zinc Level in Neonates with Indirect Hyperbilirubinemia. IJMA., 2 (1): 217-222. 